\title{
Predictive modeling the side weir discharge coefficient using neural network
}

\author{
Abbas Parsaie ${ }^{1}$ \\ Received: 16 January 2016/ Accepted: 18 March 2016/Published online: 2 April 2016 \\ (C) Springer International Publishing Switzerland 2016
}

\begin{abstract}
Weirs are common structures that are widely used in the almost water engineering projects such as hydropower systems, irrigation and drainage networks along with sewage networks. A side weir has many possible uses in hydraulic engineering and has been investigated as an important structure in hydro systems, as well. In this paper, predicting the discharge coefficient of side weirs $\left(C d_{s w}\right)$ was considered using the empirical formulas, multilayer perceptron (MLP) and radial basis function (RBF) neural network as delegate of artificial neural network models. The results indicate that Emiroglu formula by correlation coefficient of $\left(\mathrm{R}^{2}=0.65\right)$ and root mean square error of $(\mathrm{RMSE}=0.03)$ is the accurate one among the empirical formulas. Evaluating the performance of the RBF model with ten neurons in the hidden layer involving error indices of $\left(\mathrm{R}^{2}=0.71\right.$ and $\left.\mathrm{RMSE}=0.08\right)$ showed that this model was a bit better than Emiroglu formula. The structure of MLP model was considered as similar to RBF model whereas the tangent sigmoid was used instead to the radial basis function. The results of MLP model showed that this model with $\mathrm{R}^{2}=0.89$ and $\mathrm{RMSE}=0.067 \mathrm{had}$ suitable performance for predicting discharge coefficient. Performance of MLP was more accurate compared to RBF model.
\end{abstract}

Keywords Weirs - Discharge coefficient $\cdot$ Empirical formulas $\cdot$ Multi-layer perceptron (MLP)

Abbas Parsaie

abbas_parsaie@yahoo.com

1 Department of Water Engineering, Lorestan University, Khorramabad, Iran

\section{Introduction}

Modeling of hydraulic structure has received much attention in recent years due to its effect on increasing hydro system performance (Dehdar-behbahani and Parsaie 2016; Parsaie et al. 2015b). Weirs are common structures, which are widely used in most water engineering projects such as hydropower systems, irrigation and drainage networks and sewage networks (Haghiabi 2012). Side weir is a type of weir which has many possible uses in hydraulic engineering and has been investigated as an important structure in hydro systems as well (Chen 2015; Laycock 2007). Side weir is a hydraulic structure placed on the side of the channel and sometime is used as water surface controller structure in dam and irrigation projects whereas the main task of side weirs is removing the excess flow from the hydro systems (Bagheri et al. 2014; Haddadi and Rahimpour 2012). Study on side weirs hydraulics is conducted by the physical and numerical approaches (Parsaie 2016). In the field of physical studies, researchers attempted to improve the performance of side weirs by proposing various shapes for the crest of the side weir and compared its performance with rectangular shape as standard form for side weir. In this regard, labyrinth, oblique, semi-elliptical, curved plan-form and trapezoidal sharp and broad-crested could be mentioned. Based on reports, performance of nonlinear weirs is much more than the conventional side weir (Borghei and Parvaneh 2011; Cheong 1991; Coşar and Agaccioglu 2004; Emiroglu and Kaya 2011; Emiroglu and Kisi 2013; Emiroglu et al. 2011a; Haddadi and Rahimpour 2012; Jalili and Borghei 1996; Kaya et al. 2011). In the field of numerical modeling, in addition to solving the governing hydraulic equations by numerical approaches such as Runge-Kutta Method, the computational fluid dynamic (CFD) techniques has been used to simulate the flow over side weir. 
Numerical solution of governing equations leads to defining hydraulic parameters such as water surface profile, distribution of velocity and pressure and flow pattern (Aydin and Emiroglu 2013; Parsaie and Haghiabi 2015b). Another way for numerical modeling is related to the use of soft computing techniques for predicting the hydraulic properties of side weirs such as discharge coefficient (Azamathulla et al. 2016). In this regard, researchers used artificial neural network (ANNs), group method of data handling (GMDH), gene expression programming (GEP), and adaptive neurofuzzy inference system (ANFIS). Developing ANN models is based on data set, which means that to predict the hydraulic phenomenon by neural network techniques, parameters that influence the phenomenon should be measured in the past. ANN models could be used as standalone and be applied as participant of numerical methods in numerical simulation as well to increase the accuracy of the numerical modeling. The results of using the mentioned neural network models indicate that ANN models are more accurate (Bilhan et al. 2010; Bilhan et al. 2011; Ebtehaj et al. 2015a, b; Emiroglu and Kisi 2013; Emiroglu et al. 2011b; Kisi et al. 2012; Parsaie and Haghiabi 2015b). In this research, the radial basis function (RBF) neural network that has high performance in pattern recognition and image processing is used for predicting the side weir discharge coefficient, and its performance is compared with empirical formula and multilayer perceptron neural network as common ANN model, which is used by most researchers.

\section{Materials and method}

Figure 1 shows a schematic shape of a side weir in subcritical flow condition. The discharge coefficient of side weir is a function of hydraulic characteristics and geometry of side weir and main channel. Most hydraulic and geometry parameters are shown in Fig. 1.

As could be seen in Fig. $1, V_{1}$ and $Q_{1}$ are the velocity and discharge of flow at beginning the side weir respectively; $\mathrm{B}$ : width of main channel; $\mathrm{E}$ : specific energy; $h_{1}$ : depth of flow at beginning the side weir; $h$ : the flow over side weir; $h_{2}$ : depth of flow at the end of side weir; L: side weir length; P: weir height and the longitudinal slope of the channel $\left(\mathrm{S}_{0}\right)$. Defining the effect of each effective parameter requires conducting experiments in the condition that other parameters are constant. Researchers who conducted experimental studies on the hydraulics of side weirs proposed empirical equations for calculating the side weir discharge coefficient. A summary of the most famous empirical formulas is given in Table 1.

Researchers attempt to reduce the number of experiments using the dimensional analysis techniques such as Buckingham $\pi$ theory. Using analysis techniques leads to derive dimensionless parameters. Dimensionless parameters which influence the discharge coefficient of side weirs are given in Eq. (1) (Emiroglu et al. 2011a).

$C d_{s w}=f_{2}\left(F r_{1}, \frac{L}{B}, \frac{L}{h_{1}}, \frac{P}{h_{1}}\right)$

In Eq. (1), $F r_{1}$ is the Froude number, $\frac{L}{B}$ describes the ratio of weir length to the width of main channel, $\frac{L}{h_{1}}$ describes the ratio of weir length to the flow depth at beginning the weir, and $\frac{P}{h_{1}}$ describes the ratio of weir height to the flow depth at the beginning the weir. As presented in Table 1, most empirical formulas have used dimensionless parameters. Using dimensionless parameters in ANN model preparation leads to developing optimal structure. Developing MLP and RBF models
Fig. 1 Sketch of side weir structure in subcritical flow condition

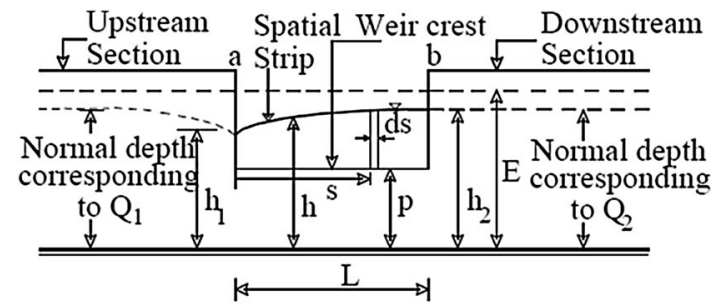

(a)

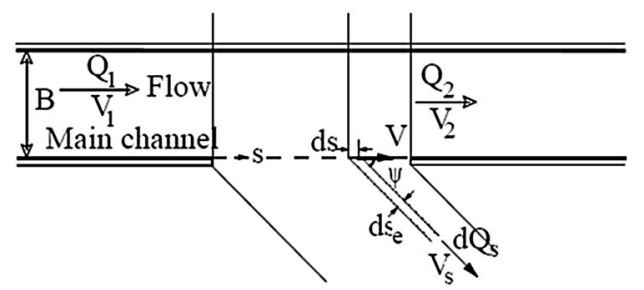

(b)

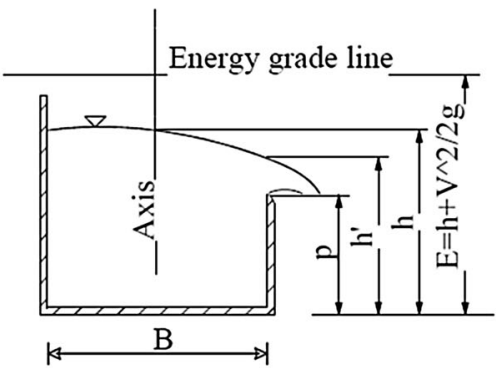

(c) 
Table 1 Some empirical formulas to calculate side weir discharge coefficient

\begin{tabular}{lll}
\hline Row & Author & Equation \\
\hline 1 & $\begin{array}{l}\text { Nandesamoorthy and Thomson } \\
\text { (1972) }\end{array}$ & $C_{d}=0.432\left(\frac{2-F r_{1}^{2}}{1+2 F r_{1}^{2}}\right)^{0.5}$ \\
2 & Subramanya and Awasthy (1972) & $C_{d}=0.864\left(\frac{1-F r_{1}^{2}}{2+F r_{1}^{2}}\right)^{0.5}$ \\
3 & Yu-Tech (1972) & $C_{d}=0.623-0.222 F r_{1}$ \\
4 & Ranga Raju et al. (1979) & $C_{d}=0.81-0.6 F r_{1}$ \\
5 & Hager (1987) & $C_{d}=0.485\left(\frac{2-F r_{1}^{2}}{2+3 F r_{1}^{2}}\right)^{0.5}$ \\
6 & Cheong (1991) & $C_{d}=0.45-0.221 F r_{1}$ \\
7 & Singh et al. (1994) & $C_{d}=0.33-0.18 F r_{1}+0.49\left(\frac{P}{h_{1}}\right)$ \\
8 & Jalili and Borghei (1996) & $C_{d}=0.71-0.41 F r_{1}+0.22\left(\frac{P}{h_{1}}\right)$ \\
9 & Borghei et al. (1999) & $C_{d}=0.7-0.48 F r_{1}+0.3\left(\frac{P}{h_{1}}\right)+0.06\left(\frac{L}{h_{1}}\right)$ \\
10 & Emiroglu et al. (Emiroglu et al. & \\
& 2011a, b) & $C_{d}=\left[0.836+\left(-0.035+0.39\left(\frac{P}{h_{1}}\right)^{12.69}+0.158\left(\frac{L}{b}\right)^{0.59}+0.049\left(\frac{L}{h_{1}}\right)^{0.42}+0.244 F r_{1}^{2.125}\right)^{3.018}\right.$ \\
\hline
\end{tabular}

Table 2 Range of collected data related to the side weir discharge coefficient

\begin{tabular}{llllrl}
\hline Data range & $\mathrm{Fr}_{1}$ & $\mathrm{P} / \mathrm{h}_{1}$ & $\mathrm{~L} / \mathrm{b}$ & $\mathrm{L} / \mathrm{h}_{1}$ & $\mathrm{Cd}$ \\
\hline Min & 0.09 & 0.03 & 0.21 & 0.19 & 0.09 \\
Max & 0.84 & 2.28 & 3.00 & 10.71 & 1.75 \\
Avg & 0.43 & 0.76 & 1.13 & 3.87 & 0.50 \\
STDEV & 0.18 & 0.43 & 0.85 & 3.06 & 0.17 \\
\hline
\end{tabular}

similar to other neural network models is based on data set. To do so, 477 data sets related to side weir discharge coefficient, published in creditable journals were collected. Some of resources used for data derivation are given as follows (Bagheri et al. 2014; Borghei et al. 1999; Emiroglu et al. 2011a; Singh et al. 1994; Subramanya and Awasthy 1972). The range of collected data is given Table 2.

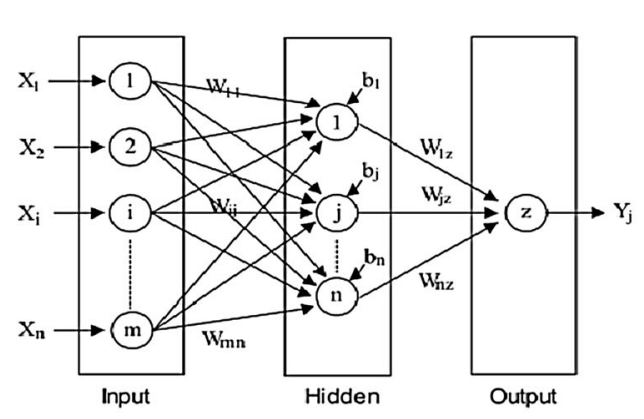

Fig. 2 A three-layer ANN architecture

\section{Multilayer perceptron (MLP) neural network}

ANN is a nonlinear mathematical model that is able to simulate arbitrarily complex nonlinear processes, which relate inputs and outputs of any system. In many complex mathematical problems that lead to solving complex nonlinear equations, Multilayer perceptron networks are common types of ANN widely used by researchers. To use MLP model, definition of appropriate functions, weights and bias should be considered. Due to the nature of the problem, different activity functions in neurons could be used. An ANN may have one or more hidden layers. Figure 2 demonstrates a three-layer neural network consisting of inputs layer, hidden layer (layers) and outputs layer. As shown in Fig. 2, $n w_{i}$ is the weight and $b_{i}$ is the bias for each neuron. Weight and biases values will be assigned progressively and corrected during training process comparing the predicted outputs with known outputs. Such networks are

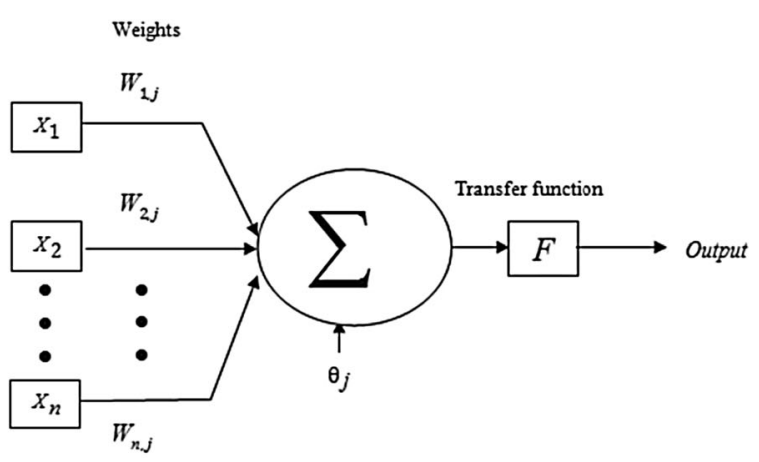




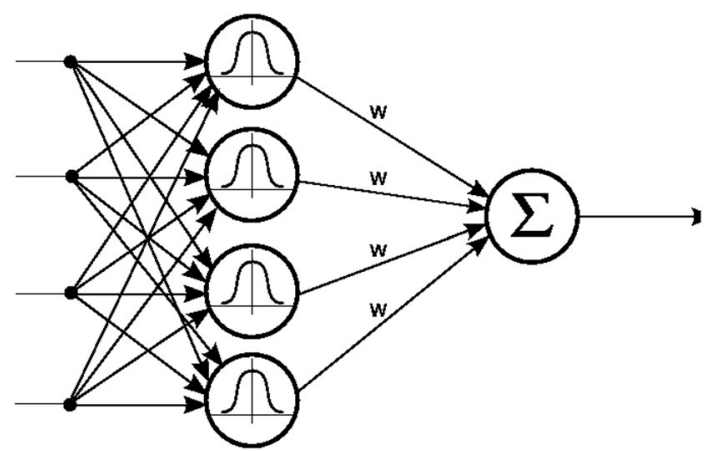

Fig. 3 A RBF model structure
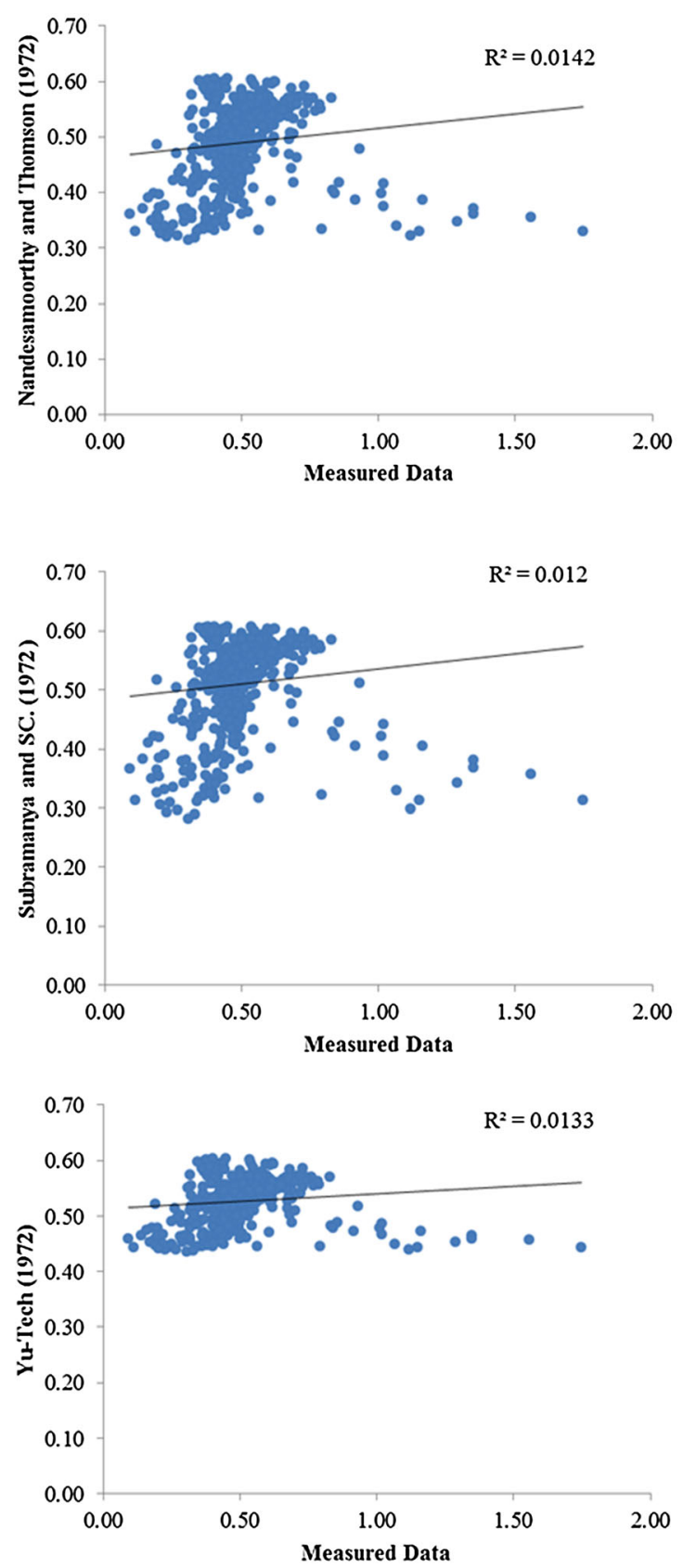

Fig. 4 Results of empirical formulas versus measured data often trained using back propagation algorithm. In the present study, ANN was trained by Levenberg-Marquardt technique because this technique is more powerful and faster compared to the conventional gradient descent technique (Parsaie and Haghiabi 2015a; Parsaie et al. 2015a).

\section{Radial basis function (RBF) neural network}

Radial basis function (RBF) neural network is a type of artificial neural network widely used in image processing, pattern recognition and nonlinear system modeling. RBF
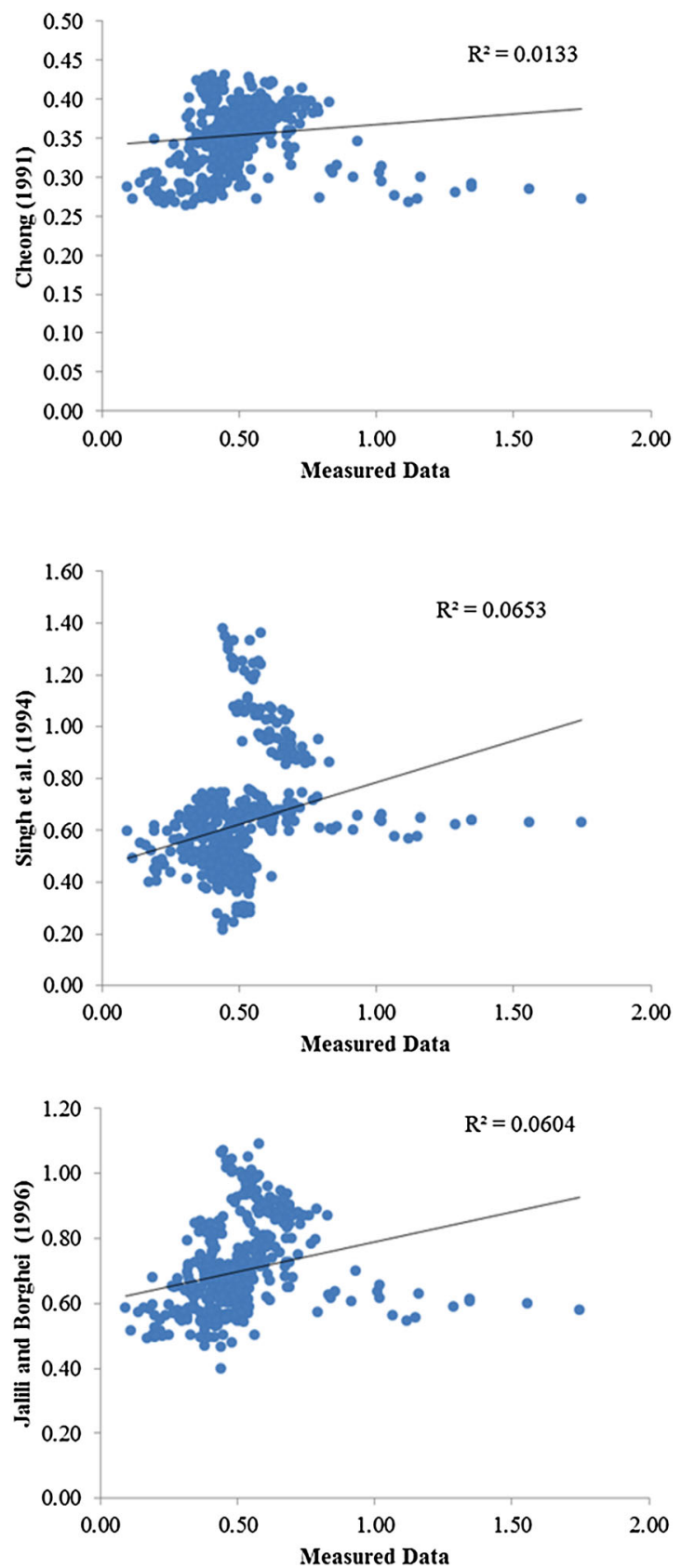

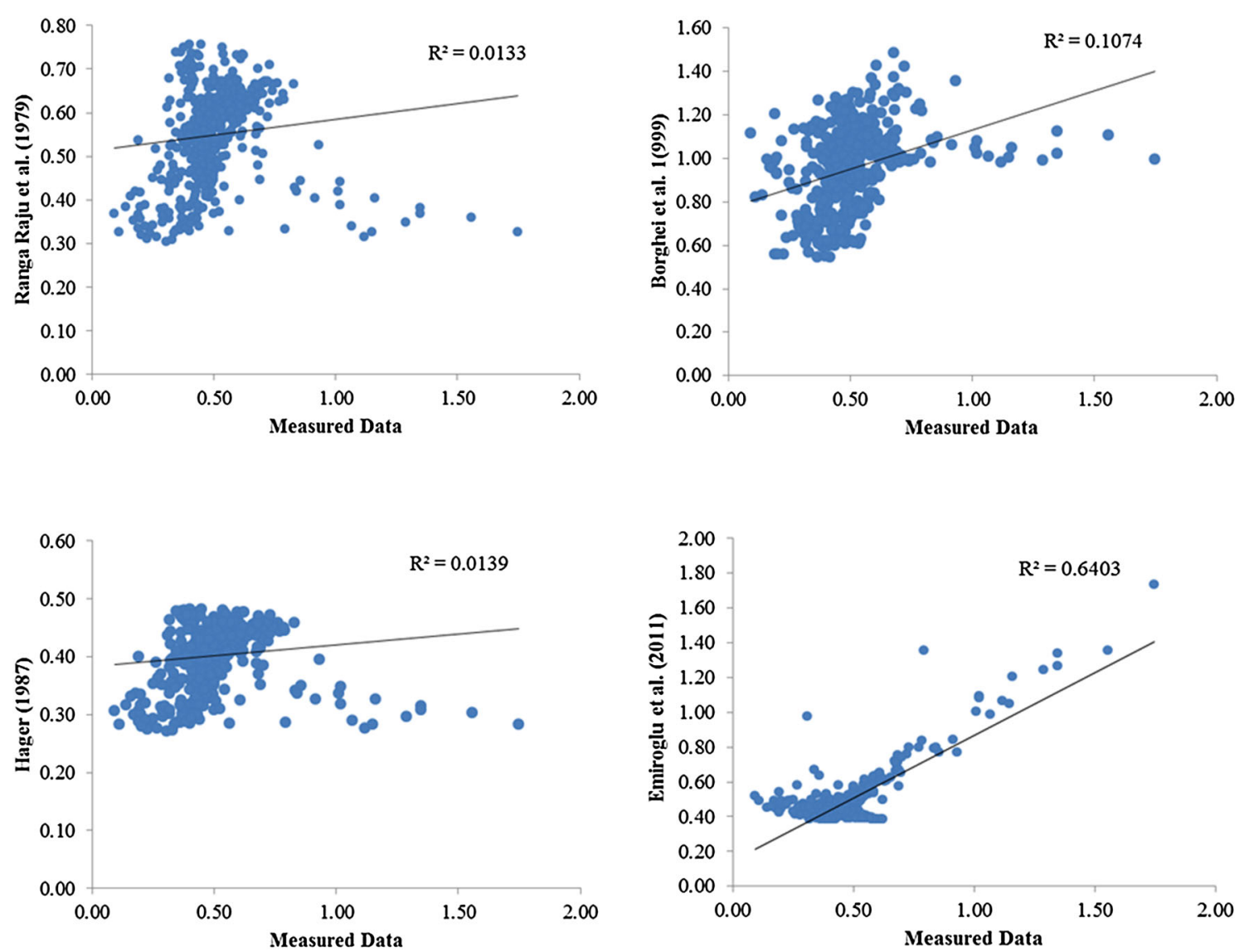

Fig. 4 continued

Table 3 Performance of empirical formulas

\begin{tabular}{lll}
\hline Author & $\mathrm{R}^{2}$ & RMSE \\
\hline Nandesamoorthy and Thomson (1972) & 0.01 & 0.00 \\
Subramanya and Awasthy (1972) & 0.01 & 0.00 \\
Yu-Tech (1972) & 0.01 & 0.00 \\
Ranga Raju et al. (1979) & 0.01 & 0.00 \\
Hager (1987) & 0.01 & 0.01 \\
Cheong (1991) & 0.01 & 0.01 \\
Singh et al. (1994) & 0.07 & 0.01 \\
Jalili and Borghei (1996) & 0.06 & 0.01 \\
Borghei et al. 1(999) & 0.11 & 0.02 \\
Emiroglu et al. (2011a, b) & 0.65 & 0.03 \\
\hline
\end{tabular}

model as shown in the Fig. 3, consists of two layers, the first layer considered as hidden layer and the second one as output layer. The radial function is considered as transfer function for neurons, which are in hidden layer and linear function as output layer transfer function. Designing RBF neural network is based on defining the center of these functions. In other words, the aim of RBF model training is mapping the input space to output space as $f: R^{n} \rightarrow R$. Transfer function of the RBF model is defined as Eq. (2).

$f(v)=\sum_{i=1}^{n} w_{i} \varphi\left(\left\|v-c_{i}\right\|\right)$

where $v$ is the inputs variable, $w_{i}$ is the weight coefficients, $\varphi$ is Gaussian function, which is the basic function used as kernel function in RBF model development and is defined as Eq. (3).

$\varphi(v)=e^{\left(\frac{-v^{2}}{2 \sigma^{2}}\right)}$

RBF model training usually is carried out by Gradient Descent approach. The aim of RBF model is defining the value of kernel function parameters and weights. Initial value of weights is defined randomly. The error for each sample of the data set is calculated as Eq. (4).

$e_{i}=t_{i}-y_{i}=t_{i}-\sum_{j=}^{N} w_{j} \varphi\left(\left\|v_{i}-c_{i}\right\|\right)$

The error for total input data set is calculated as Eq. (5). 
$E=\frac{1}{2} \sum_{i=1}^{p}\left|e_{i}\right|^{2}$

RBF model preparation is finished when error of RBF model for all data sets is lower than the threshold error which is defined by the designer (Liu 2013).

\section{Results and discussion}

Performance of empirical formulas, MLP and RBF models was assessed by data collected the range of which is given in Table 2. Accuracy of empirical formulas and MLP and RBF models was assessed by statistical error indices such

Fig. 5 Structure of MLP model

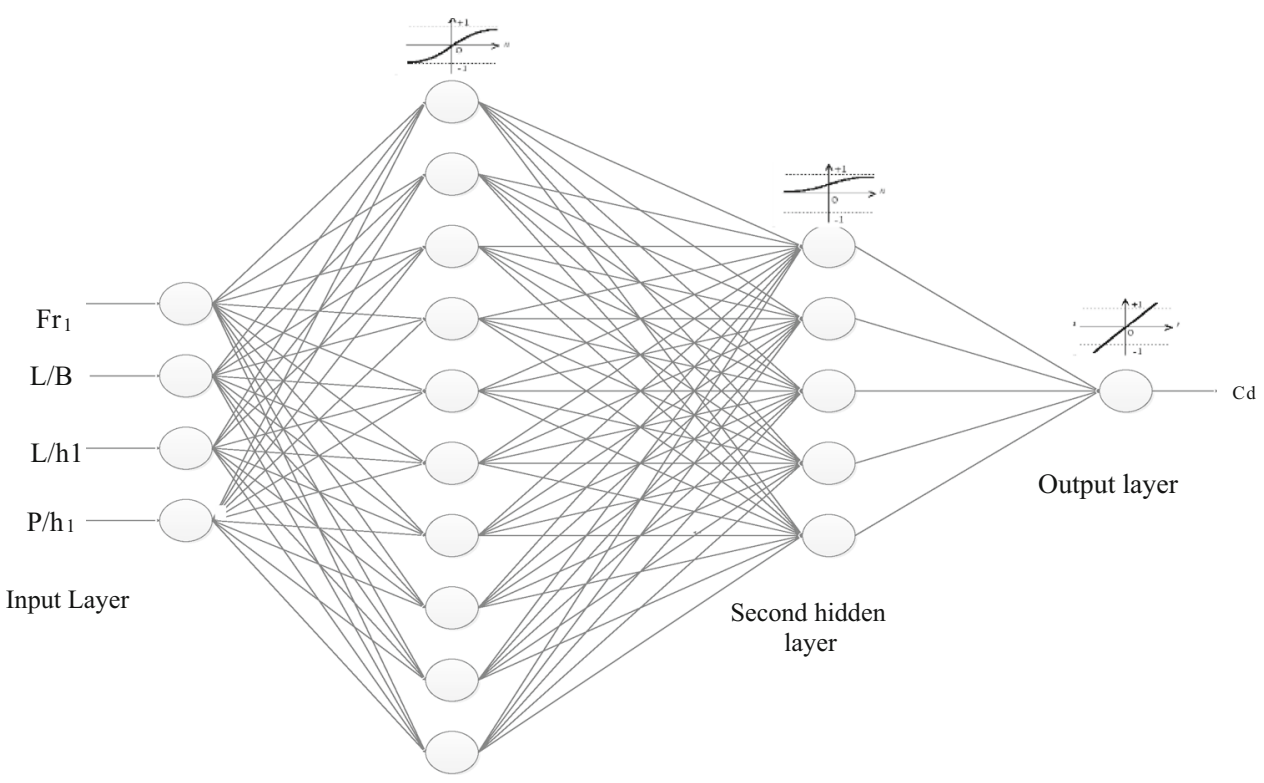

Frist hidden layer
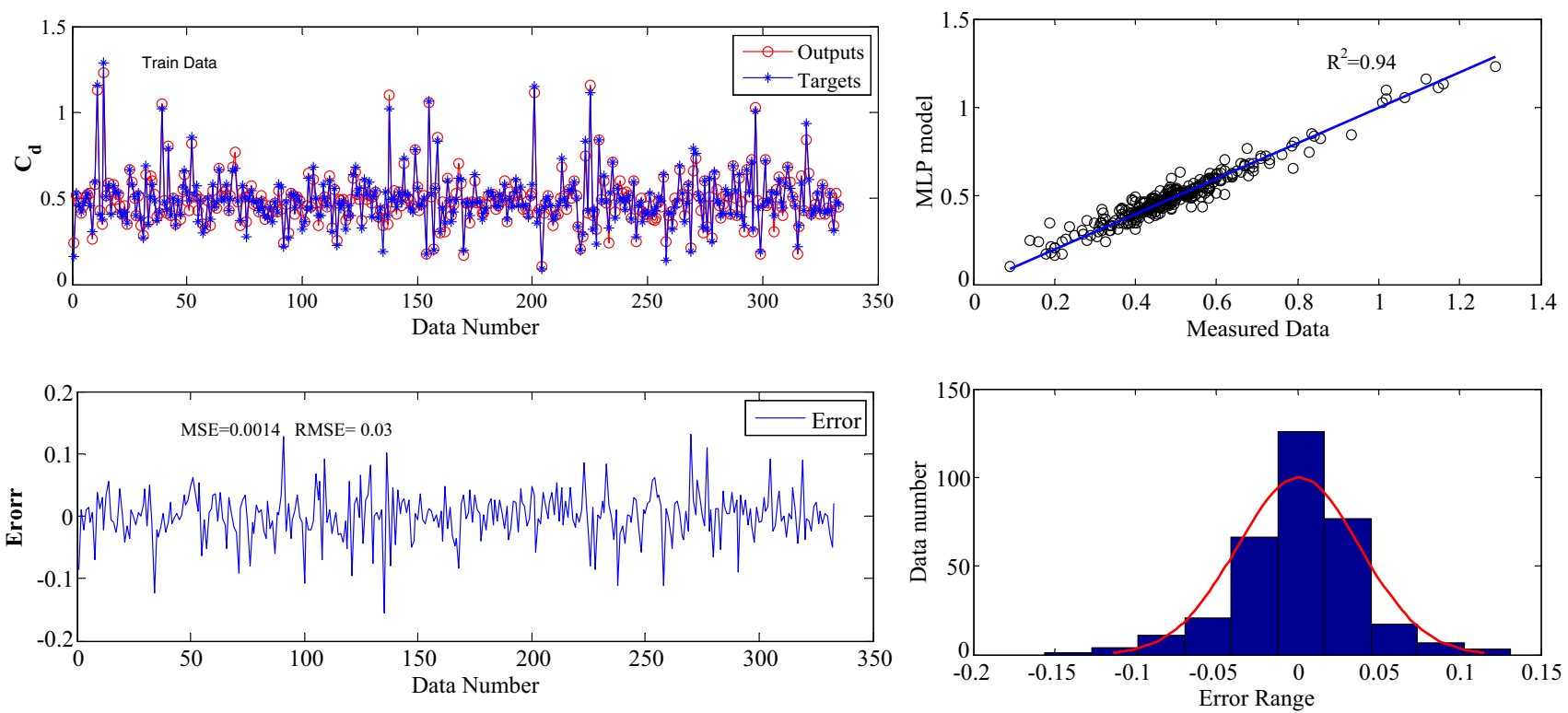

Fig. 6 Performance of MLP model during training stage 
as correlation coefficient, root mean square error (RMSE), mean square error (RMSE). It is noticeable that these indices provide an average value for error and do not provide any information about error distribution. All stages of MLP and RBF models' development have been programed in Matlab software.

\section{Results of experimental formulas}

Performance of empirical formulas was evaluated for calculating the $C d_{s w}$ using data collection (Table 2) and the results of them were compared with measured data. Figure 4 and Table 3 present the results of empirical formulas.
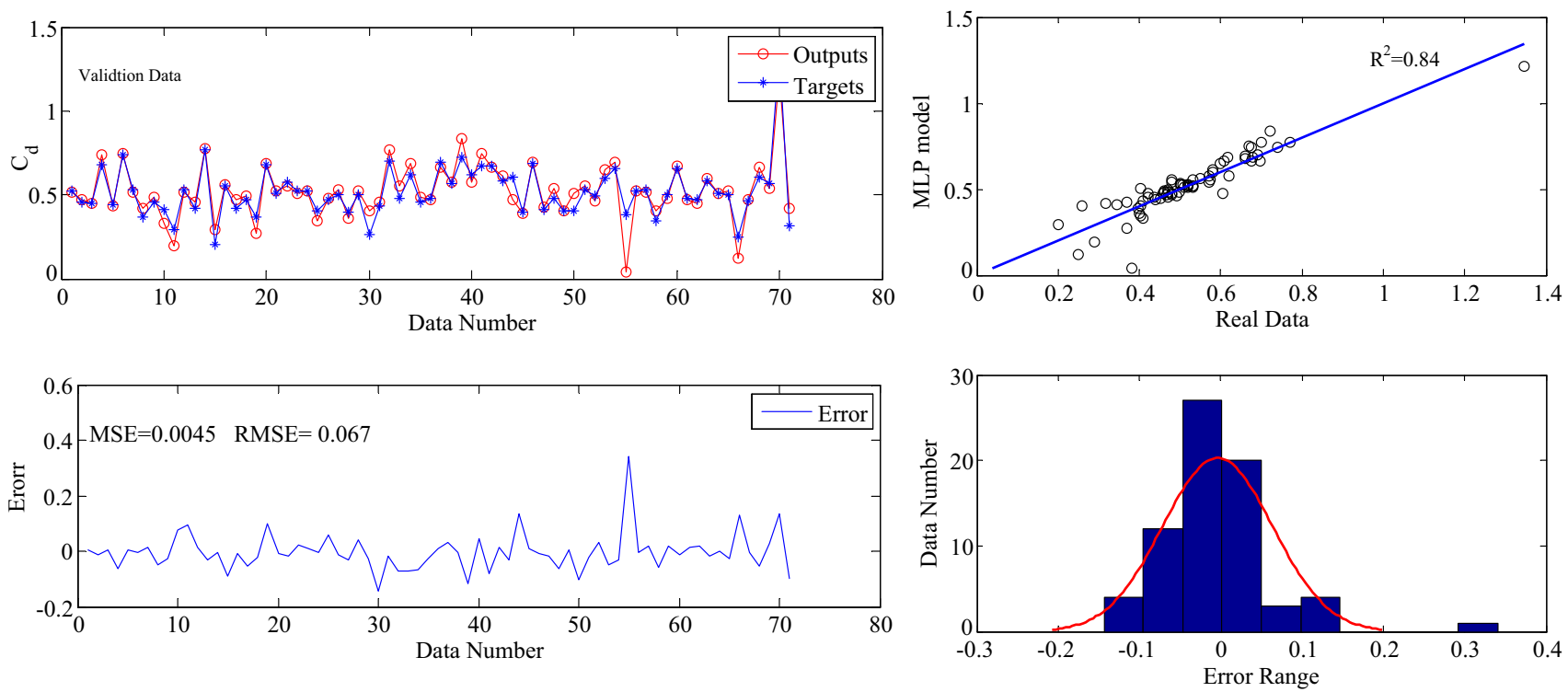

Fig. 7 Performance of MLP model during validation stage
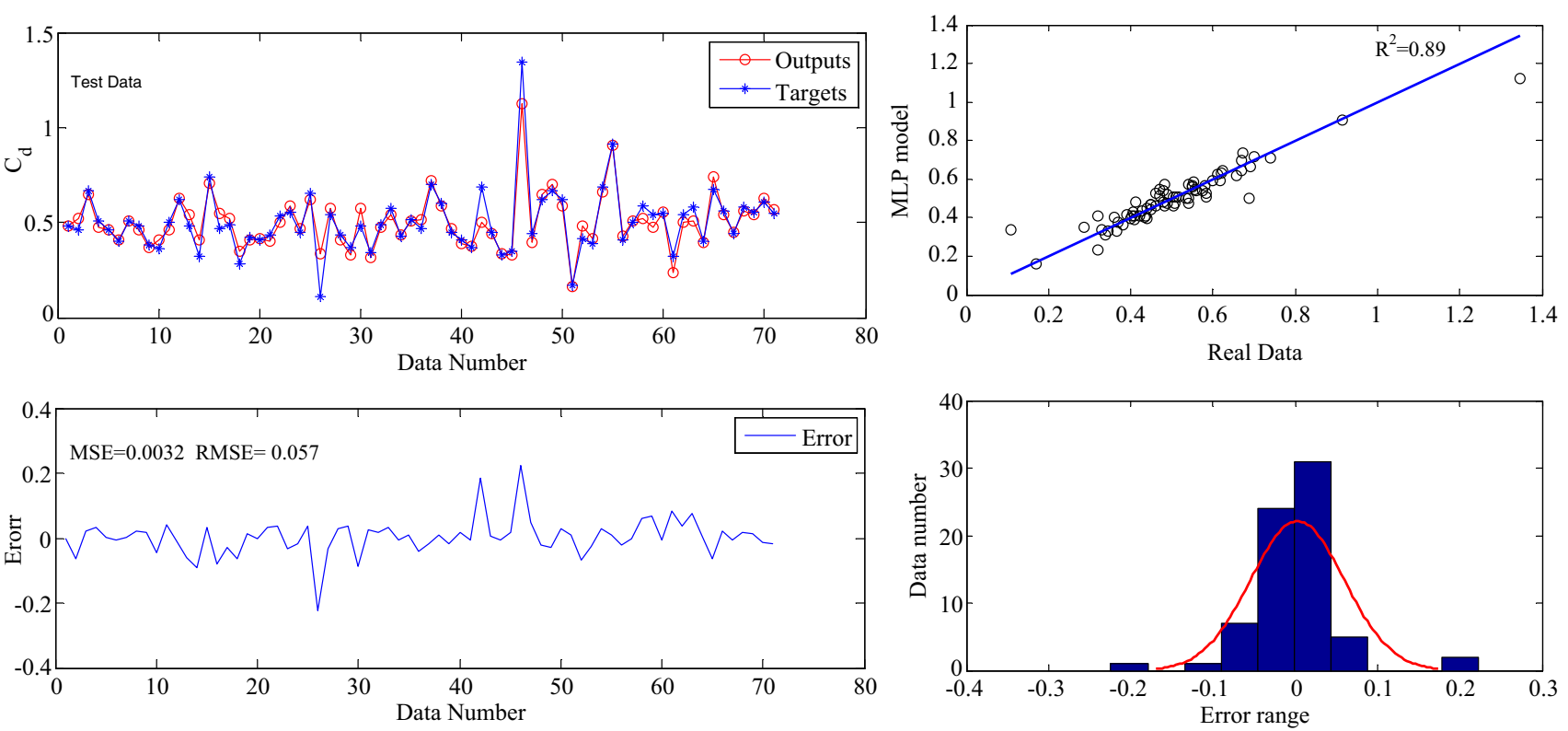

Fig. 8 Performance of MLP model during testing stage 
As could be seen in Table 3, most empirical formula do not provide suitable performance. Emiroglu formula with error indices $\left(\mathrm{R}^{2}=64\right.$ and $\left.\mathrm{RMSE}=0.03\right)$ is the most accurate one among empirical formulas.

\section{Results of ANNs models}

\section{ANNs model development}

Developing ANNs model as a common type of soft computing technique is based on data set. Therefore, the collected data set was divided into three groups as training, validation and testing. Validation data set was considered to avoid over-training of MLP model. The dimensionless

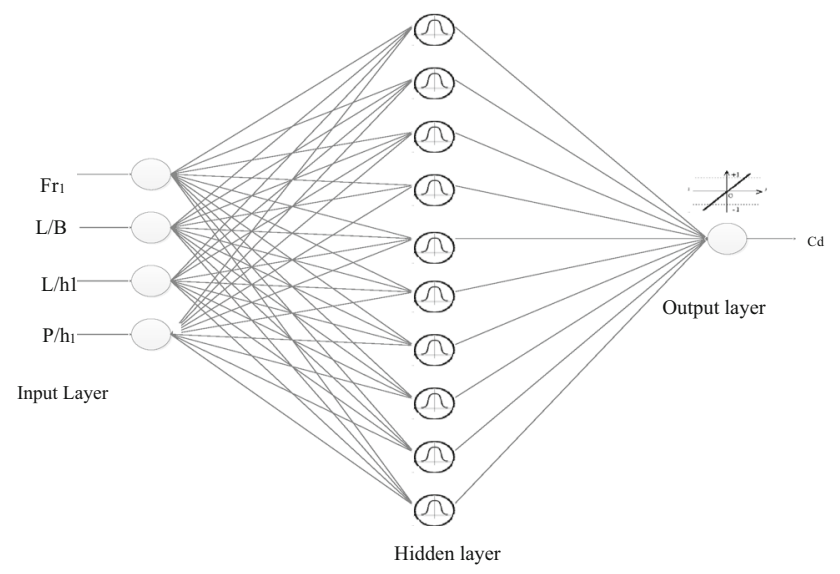

Fig. 9 Architecture of RBF model parameters presented in Eq. (1), were desirable as input parameters for ANNs model development and discharge coefficient was considered as model output. Data selection for preparation of MLP model was carried out randomly. $70 \%$ of total data set was considered for training, $15 \%$ for validation and the rest $(15 \%)$ for testing. Designing the structure of MLP model is more based on the designer experience whereas recommendation of investigators who conducted similar researches is useful. In this paper, the recommendation of Parsaie and Haghiabi (2015c) was used. Preparation of ANNs model included the type of ANNs model, number of the hidden layer(s), number of the neurons in each hidden layer, defining suitable transfer function for neurons of hidden layer(s), defining suitable transfer function for output layer and learning algorithm. To obtain an optimal structure for MLP model, first, one hidden layer was considered and then, the number of neurons in hidden layer was increased one by one. Various types of transfer functions such as log-sigmoid (logsig), tan-sigmoid (tansig), linear (purelin), etc. were tested. This process continues to obtain a model with suitable performance. It is notable that Levenberg-Marquardt technique was used for MLP model learning. All stages of MLP preparation were conducted in Matlab software.

\section{Results of MLP models}

MLP model contains two hidden layers. The first hidden layer contains ten (10) neurons with tangent sigmoid (tansig) as transfer function and the second one contains five neurons with Log-sigmoid transfer function. The
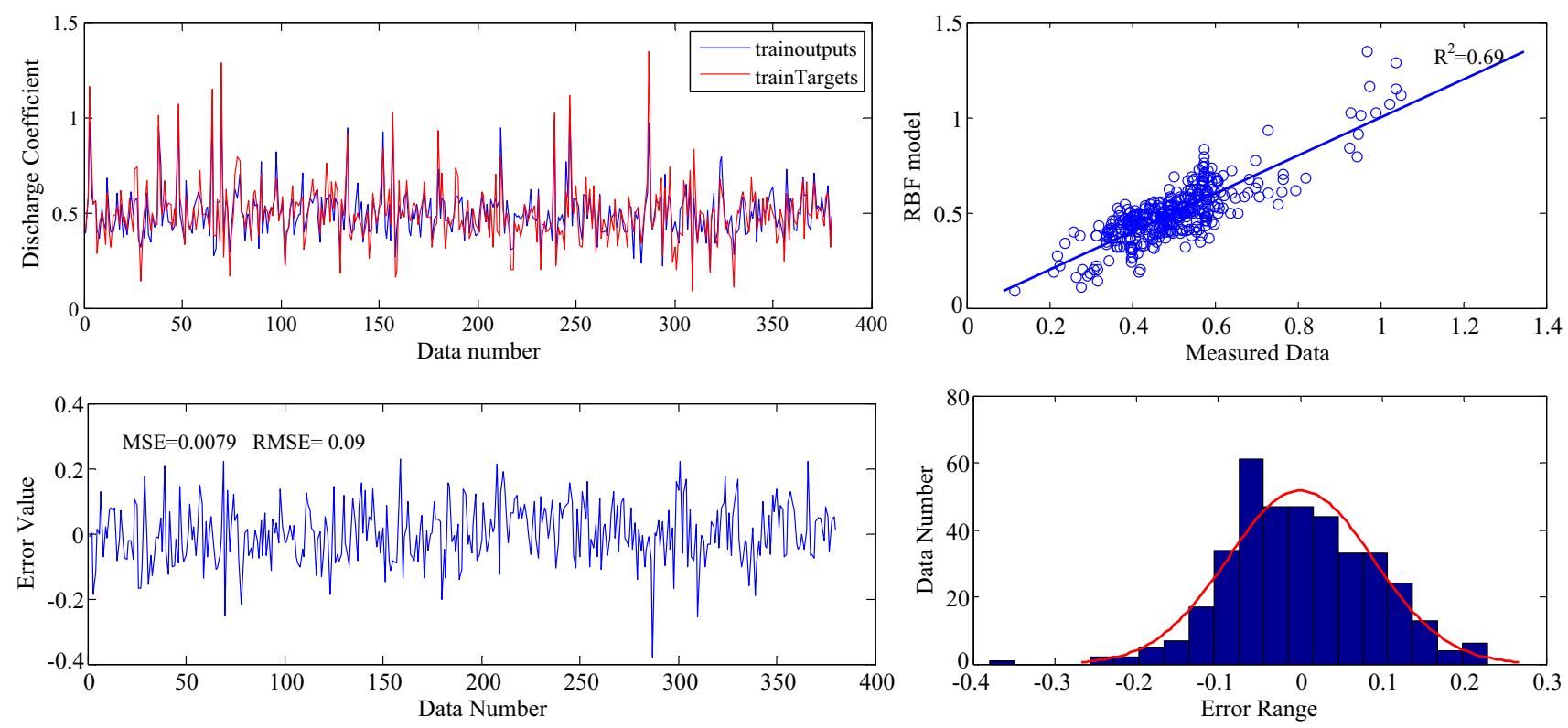

Fig. 10 Performance of RBF model during training stage 
linear transfer function was considered as neuron of output layer. The structure of developed MLP model is shown in Fig. 5. Training of MLP model was performed with Levenberg-Marquat technique. $70 \%$ of data set was used for training, $15 \%$ for validation and the rest $(15 \%)$ was considered for testing the model. Performance of MLP model in each stage of development (training, validation and testing) is shown in Figs. 6, 7, 8 and to assess the performance of this model, error indices for each stage of preparation were calculated and presented in these figures. Figures 6, 7,8) show that accuracy of MLP model is suitable for prediction of the $C d_{s w}$. In addition to calculation, standard error indices the error distribution were also plotted for the all data, which were used for training, validation and testing. To evaluate error density, error histogram was plotted. As could be seen in histogram, distribution of error is normal and more concentrated around zeros.
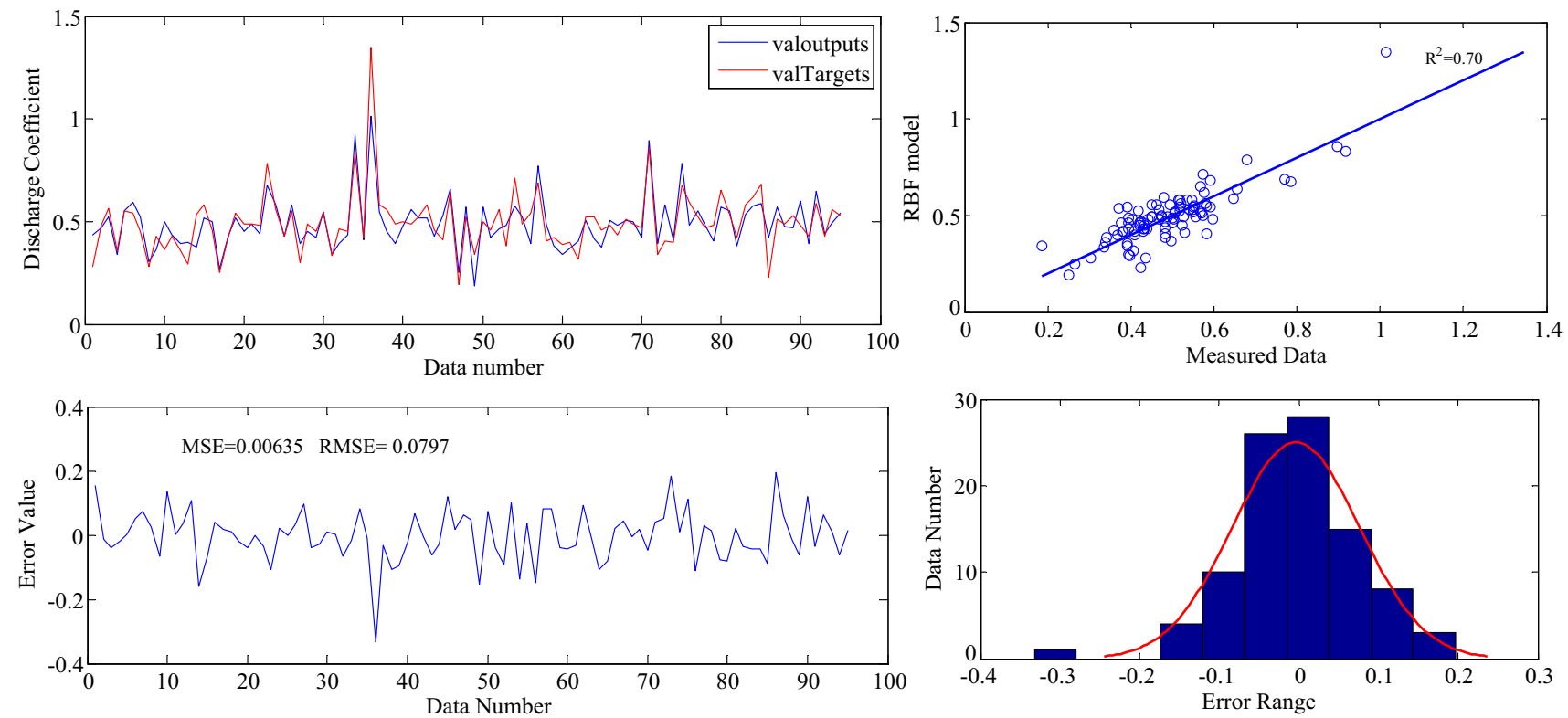

Fig. 11 Performance of RBF model during validation stage
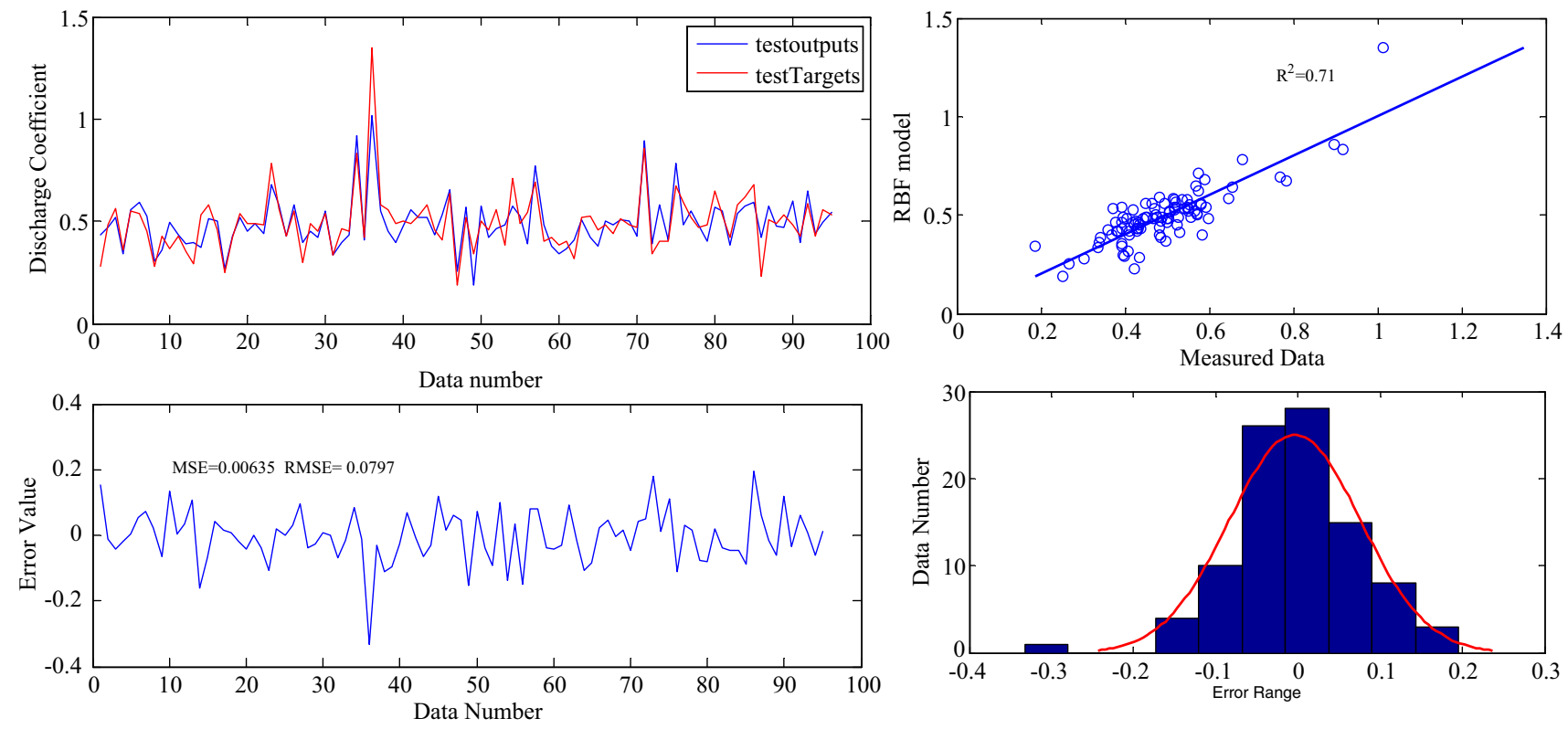

Fig. 12 Performance of MLP model during validation stage 


\section{Results of RBF models}

To assess the accuracy of RBF model to predict $C d_{s w}$ and compering its performance with MLP model, it has been attempted to hold similar conditions for model development. In other words, it has been attempted to hold similar number of the training, validation and testing data set. In addition, it has been attempted to hold similar number of neurons in input layer. The architect of RBF model is shown in Fig. 9. As shown in Fig. 9, the input layer neurons were considered equal to MLP model input later. Performance of RBF model during training, validation and testing model is shown in Figs. 10, 11, 12. As shown in these figures, performance of RBF model to predict $C d_{s w}$ is not suitable. Comparing performance of RBF model with MLP model in training, validation and testing stages shows that MLP model is more accurate.

\section{Conclusion}

In this study, side weir discharge coefficient $\left(C d_{s w}\right)$ was calculated and predicted by empirical formulas and radial basis function (RBF) neural network along with multilayer perceptron (MLP) neural network. Results of this study indicate that Emiroglu formula is the most accurate one among empirical formulas. To achieve more accuracy in $C d_{s w}$ prediction, MLP model and RBF model were developed and to prepare MLP and RBF models, about 477 data sets related to $C d_{s w}$ were collected. Results of assessing performance of MLP show that MLP model has suitable performance to predict $C d_{s w}$. Results of RBF model development indicated the accuracy of this model is a little better compared to empirical formals. In general, performance of MLP model is much more compared to RBF and empirical formulas.

\section{Compliance with ethical standards}

Conflict of interest The authors declare that there is no conflict of interest regarding the publication of this manuscript.

\section{References}

Aydin MC, Emiroglu ME (2013) Determination of capacity of labyrinth side weir by CFD. Flow Meas Instrum 29:1-8. doi:10. 1016/j.flowmeasinst.2012.09.008

Azamathulla HM, Haghiabi AH, Parsaie A (2016) Prediction of side weir discharge coefficient by support vector machine technique. Water Sci Technol Water Supply. doi:10.2166/ws.2016.014

Bagheri S, Kabiri-Samani AR, Heidarpour M (2014) Discharge coefficient of rectangular sharp-crested side weirs, Part I: traditional weir equation. Flow Meas Instrum 35:109-115. doi:10.1016/j.flowmeasinst.2013.11.005
Bilhan O, Emin Emiroglu M, Kisi O (2010) Application of two different neural network techniques to lateral outflow over rectangular side weirs located on a straight channel. Adv Eng Softw 41:831-837. doi:10.1016/j.advengsoft.2010.03.001

Bilhan O, Emiroglu ME, Kisi O (2011) Use of artificial neural networks for prediction of discharge coefficient of triangular labyrinth side weir in curved channels. Adv Eng Softw 42:208-214. doi:10.1016/j.advengsoft.2011.02.006

Borghei SM, Parvaneh A (2011) Discharge characteristics of a modified oblique side weir in subcritical flow. Flow Meas Instrum 22:370-376. doi:10.1016/j.flowmeasinst.2011.04.009

Borghei S, Jalili M, Ghodsian M (1999) Discharge coefficient for sharpcrested side weir in subcritical flow. J Hydraul Eng 125: 1051-1056. doi:10.1061/(ASCE)0733-9429(1999)125:10(1051)

Chen SH (2015) Hydraulic structures. Springer, Berlin

Cheong H (1991) Discharge coefficient of lateral diversion from trapezoidal channel. J Irrig Drain Eng 117:461-475. doi:10. 1061/(ASCE)0733-9437(1991)117:4(461)

Coşar A, Agaccioglu H (2004) Discharge coefficient of a triangular side-weir located on a curved channel. J Irrig Drain Eng 130:410-423. doi:10.1061/(ASCE)0733-9437(2004)130:5(410)

Dehdar-behbahani S, Parsaie A (2016) Numerical modeling of flow pattern in dam spillway's guide wall. Case study: Balaroud dam, Iran. Alex Eng J 55(1):467-473

Ebtehaj I, Bonakdari H, Zaji AH, Azimi H, Khoshbin F (2015a) GMDH-type neural network approach for modeling the discharge coefficient of rectangular sharp-crested side weirs Engineering Science and Technology, an. Int J. doi:10.1016/j. jestch.2015.04.012

Ebtehaj I, Bonakdari H, Zaji AH, Azimi H, Sharifi A (2015b) Gene expression programming to predict the discharge coefficient in rectangular side weirs. Appl Soft Comput 35:618-628. doi:10. 1016/j.asoc.2015.07.003

Emiroglu M, Kaya N (2011) Discharge coefficient for trapezoidal labyrinth side weir in subcritical flow. Water Resour Manag 25:1037-1058. doi:10.1007/s11269-010-9740-7

Emiroglu M, Kisi O (2013) Prediction of discharge coefficient for trapezoidal labyrinth side weir using a neuro-fuzzy approach. Water Resour Manag 27:1473-1488. doi:10.1007/s11269-0120249-0

Emiroglu ME, Agaccioglu H, Kaya N (2011a) Discharging capacity of rectangular side weirs in straight open channels. Flow Meas Instrum 22:319-330. doi:10.1016/j.flowmeasinst.2011.04.003

Emiroglu ME, Bilhan O, Kisi O (2011b) Neural networks for estimation of discharge capacity of triangular labyrinth side-weir located on a straight channel. Expert Syst Appl 38:867-874. doi:10.1016/j.eswa.2010.07.058

Haddadi H, Rahimpour M (2012) A discharge coefficient for a trapezoidal broad-crested side weir in subcritical flow. Flow Meas Instrum 26:63-67. doi:10.1016/j.flowmeasinst.2012.04. 002

Hager W (1987) Lateral Outflow over Side Weirs. J Hydraul Eng 113(4):491-504

Haghiabi AH (2012) Hydraulic characteristics of circular crested weir based on Dressler theory. Biosyst Eng 112(4):328-334

Jalili M, Borghei S (1996) Discussion: discharge coefficient of rectangular side weirs. J Irrig Drain Eng 122:132

Kaya N, Emiroglu ME, Agaccioglu H (2011) Discharge coefficient of a semi-elliptical side weir in subcritical flow. Flow Meas Instrum 22:25-32. doi:10.1016/j.flowmeasinst.2010.11.002

Kisi O, Emin Emiroglu M, Bilhan O, Guven A (2012) Prediction of lateral outflow over triangular labyrinth side weirs under subcritical conditions using soft computing approaches. Expert Syst Appl 39:3454-3460. doi:10.1016/j.eswa.2011.09.035

Laycock A (2007) Irrigation systems: design, planning and construction. CABI, Oxfordshire 
Liu J (2013) Radial basis function (RBF) neural network control for mechanical systems: design, analysis and Matlab simulation. Springer, Berlin

Nandesamoorthy T, Thomson A (1972) Discussion of spatially varied flow over side weir. J Hydrol Eng 98(12):2234-2235

Parsaie A (2016) Analyzing the distribution of momentum and energy coefficients in compound open channel. Model Earth Syst Environ 2(1): 1-5

Parsaie A, Haghiabi A (2015a) Computational modeling of pollution transmission in rivers. Appl Water Sci. doi:10.1007/s13201-0150319-6

Parsaie A, Haghiabi A (2015b) The effect of predicting discharge coefficient by neural network on increasing the numerical modeling accuracy of flow over side weir. Water Resour Manag 29:973-985. doi:10.1007/s11269-014-0827-4

Parsaie A, Haghiabi AH (2015c) Predicting the longitudinal dispersion coefficient by radial basis function neural network. Model Earth Syst Environ 1(4):1-8
Parsaie A, Yonesi H, Najafian S (2015a) Predictive modeling of discharge in compound open channel by support vector machine technique. Model Earth Syst Environ 1:1-6. doi:10.1007/ s40808-015-0002-9

Parsaie A, Haghiabi AH, Moradinejad A (2015b) CFD modeling of flow pattern in spillway's approach channel. Sustain Water Resour Manag 1(3):245-251

Ranga Raju KG, Prasad B, Grupta SK (1979) Side weir in rectangular channels. J Hydraul Div 105:547-554

Singh R, Manivannan D, Satyanarayana T (1994) Discharge coefficient of rectangular side weirs. J Irrig Drain Eng 120:814-819. doi:10.1061/(ASCE)0733-9437(1994)120:4(814)

Subramanya K, Awasthy SC (1972) Spatially varied flow over sideweirs. J Hydraulics Div 98:1-10

Yu-Tech L (1972) Discussion of spatially varied flow over side weir. J Hydraul Eng 98(11):2046-2048 